Article

\title{
Autogenous Tumbling Media Assessment to Clean Weathered Surfaces of Waste-Rock Particles from a Basalt Quarry
}

\author{
Baran Tufan \\ Department of Mining Engineering, Dokuz Eylül University, Izmir, Turkey; \\ E-Mail: baran.tufan@deu.edu.tr; Tel.: +90-232-301-7542; Fax: +90-232-453-0868 \\ Academic Editor: Karen Hudson-Edwards
}

Received: 28 March 2015 / Accepted: 11 June 2015 / Published: 17 June 2015

\begin{abstract}
In this study, the optimum feed composition in autogenous tumbling of basalt waste-rock particles to clean their weathered surface was determined. The weathered surfaces of basalt are generally cut out consequent to extraction of basalt columns in quarry operations. The inefficiently cut out portions of basalt cause formation of huge quarry waste dumps causing visual pollution on roadsides. Mixtures of different particle size fractions of basalt waste-rock particles were experimented to achieve the optimum feed material composition. The minimum loss of commercially available basalt particles and maximum clear surface was intended. The results were compared with respect to weight loss (\%) and reflectance values of used and generated samples.
\end{abstract}

Keywords: basalt; weathered surfaces; autogenous tumbling; tumbling parameters; reflectance spectroscopy

\section{Introduction}

Basalt, a very hard extrusive igneous rock, is formed due to rapid cooling of magma at the near surface of the earth. Magmatic basalt is a fine grained, dark grey or black colored hard rock containing approximately $50 \% \mathrm{SiO}_{2}$ [1]. Basalt has many fields of utilization such as filing material, ballast material in road and railroad constructions, raw material in production of corrosion and abrasion resistant polymeric composites, production of mineral wool and thermal insulation owing to its solid, strong and chemical resistive structure [2]. 
The mechanical [3,4], thermal [4], mineralogical [5,6] and geological [5-8] studies of basaltic rocks of Turkey have been conducted by many researchers. The basalt formation of Aliaga (Izmir) region displays typical columnar joints, exhibiting weathered surfaces.

Weathered surface of columnar-jointed basalts due to weathering by oxidation of iron bearing silicate minerals in the basalt is one of the problems of basalt exploitation in both economic and environmental aspects. The weathered crust is generally cut out after the extraction of basalt columns during quarry operations. The inefficiently cut out portions of basalt cause the formation of huge waste-rock dumps in addition to economic loss. In addition, the significance of cleaning and reutilizing weathered basalt waste-rocks is obvious to prevent the negative visual impact and reduce the environmental concerns about dumps appearing on roadsides through the Aliaga district.

The aim of this research was to produce clean basalt pieces by only removing the weathered crust of the basalt waste-rocks, which would be utilized in many different fields of usage, such as blasting sands, sands used in water treatment, paving stones, ballast stones, powder and granules for construction chemicals, colorful granules for roof coating materials, sub-base sands for astro pitch, wall stones, asphalt applications, ready mixed concrete, colorful sands for parks and playgrounds, epoxy sands, processed plant soils and mineral additives, landscaping, private garden decoration, fibers and heat storage materials [9-12]. Therefore, an autogenous tumbling process was applied in a laboratory type mill to optimize the tumbling media ratios of different particle sizes of basalt. The autogenous tumbling method was selected due to its ease of installation and in situ operation opportunities in addition to time and cost effective production. Also, depending on the chemical analysis results where the chemical composition of weathered zone and the basalt itself were determined to be similar, other alternative methods were eliminated. For example, the application of acidic leach might have been performed if the altered zone had carbonated compounds, which would be easier but costly to accomplish.

Among several mixtures, we tried to determine the most effectively abrasive one with minimum commercially available product loss. The results of autogenous tumbling were compared according to the weight loss of each fraction and reflectance values of the former and latter surfaces were generated.

\section{Material and Method}

Samples of weathered basalt tailings were gathered from a dumpsite belonging to a private corporation in Caltilidere, Aliaga (Izmir, Turkey) region. The sampling was performed by a loader, collecting bulk samples from seven different locations of the dumpsite, randomly varied in particle size and blending them to form a representative cone for sampling. No additional crushing, grinding or screening operations were performed in the site. The mechanical tests were performed in Rock Mechanics Laboratory; the reflectance analyses in Electronic Materials Laboratory; the chemical analyses in Instrumental Analysis Laboratory and the samples were tumbled in Mineral Processing Laboratory of Dokuz Eylül University.

\subsection{Location and Geology}

The origin of the samples is a basalt quarry, located in the vicinity of Caltilidere village in Aliaga, Western Turkey (Figure 1). In this region, the basaltic rock contains olivine, pyroxene, biotite, apatite, 
iron oxides, feldspar, quartz and plagioclase. The elevated molten materials have been deposited within the cracks and gaps between the rocks near the surface [5].

The reserve formation, the altered columns of basalt and the dumpsite of basalt tailings are illustrated in Figure $2[11,12]$, respectively.
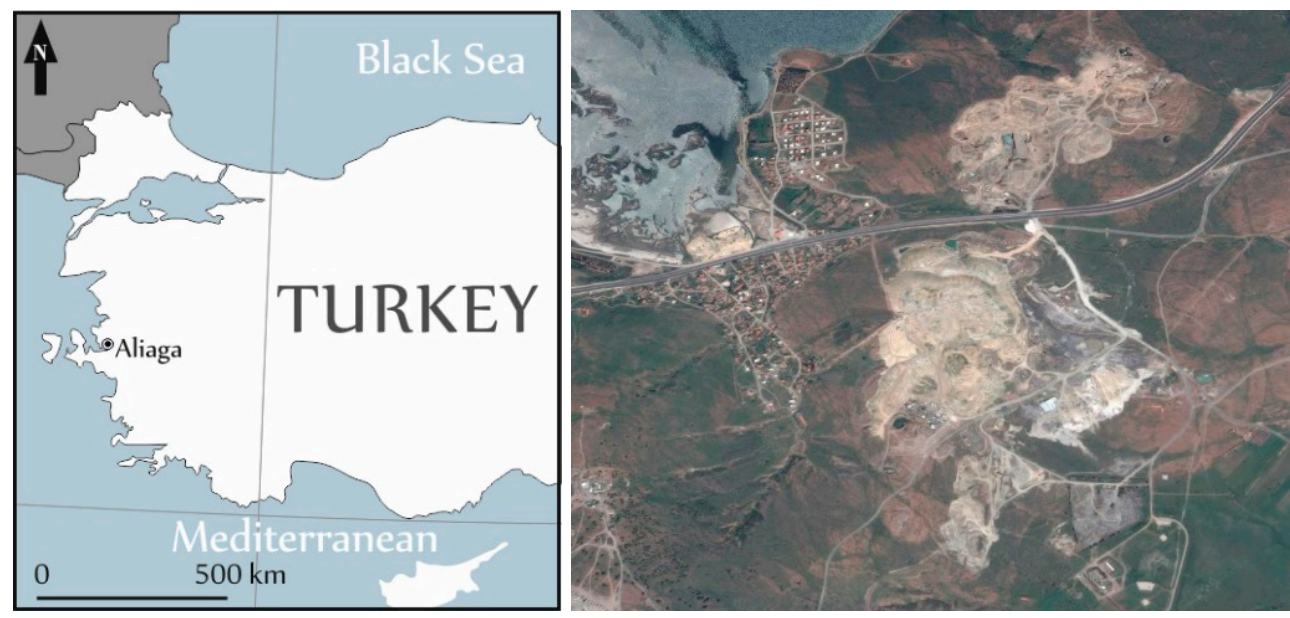

Figure 1. Location of the operational basalt quarry and the waste-rock dumpsite.

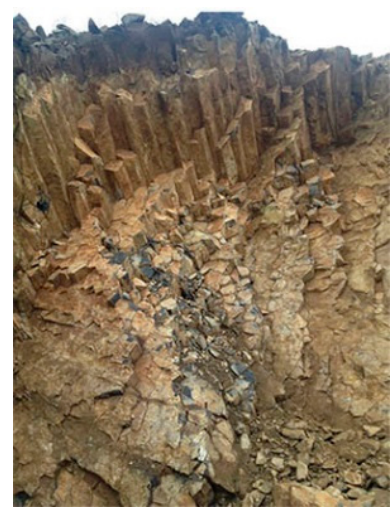

(a)

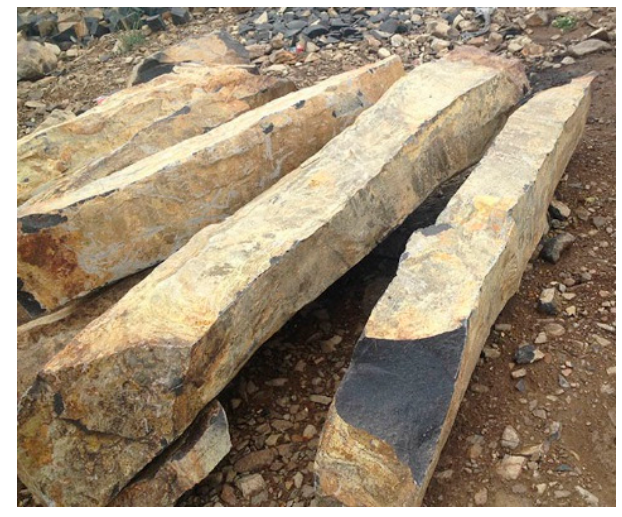

(b)

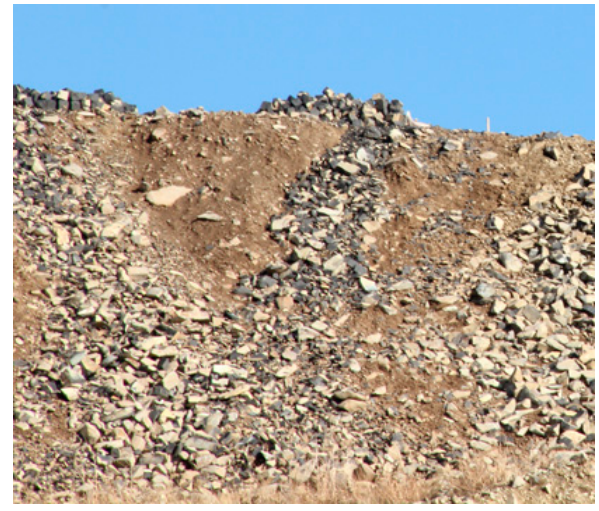

(c)

Figure 2. (a) Basalt reserve; (b) altered basalt columns (yellow to orange weathered surfaces and the dark color of unweathered rock); (c) basalt waste-rock dumpsite of the region.

\subsection{Characterization Results}

The results of the mechanical characterization of commercially available basalt samples are listed in Table 1. The density measurements were performed by MicroMetrics brand (MicroMetrics Instrument Corporation, Norcross, GA, USA), Accupyc II 1340 helium gas pycnometer, operable with both powder and granular particles up to $3.5 \mathrm{~cm}$. In uniaxial compressive strength tests of basalt samples, Ele brand (ELE International, Bedfordshire, UK) hydraulic press with 300 tons capacity was used in BS EN 1926:2006 standards [13]. The abrasion resistance tests were performed by Bohme brand surface abrasion test equipment in CSN EN 14157 standards [14].

As a well-known fact, basalt samples were revealed to be hard, strong and highly abrasive regarding the results of mechanical tests. The apparent porosity of basalt samples are relatively high, hence the pores are not interconnected. 
Table 1. Mechanical specifications of the basalt samples.

\begin{tabular}{cc}
\hline Specification & Value \\
\hline Density $\left(\mathrm{g} / \mathrm{cm}^{3}\right)$ & 2.94 \\
Hardness $(\mathrm{Mohs})$ & 5 \\
Work Index $\left(\mathrm{W}_{i}, \mathrm{kWh} / \mathrm{ton}\right)$ & 19.72 \\
Compressive Strength $\left(\mathrm{kg} / \mathrm{cm}^{2}\right)$ & 880 \\
Apparent Porosity $(\%)$ & 3.65 \\
Fill Ratio $(\%)$ & 88 \\
Water Adsorption $(\%$, by weight $)$ & 1.4 \\
Abrasion Resistance $\left(\mathrm{cm}^{3} / 50 \mathrm{~cm}^{2}\right)$ & 16.1 \\
\hline
\end{tabular}

The chemical analyses were performed on several different samples of both the basalt itself and the weathered zone of basalt (Table 2). The weathered parts which varied from 0.5 to $2 \mathrm{~mm}$ in thickness were easily stripped and removed from the basalt columns. An Analytik Jena brand atomic absorption spectroscopy was used in determination of chemical composition from the solution of ground and totally dissolved samples in double acid $\left(\mathrm{HCl}\right.$ and $\left.\mathrm{HNO}_{3}\right)$. The aim was to determine whether the weathered zone had a different chemical content or not. Hence, a different alteration process would result in a different chemical formation which might be separated from the surface of the basalt by chemical methods. However, nearly the exact compositions have been determined in both the commercially available basalt and the crust of the altered basalt tailings, which is mainly $\mathrm{SiO}_{2}$.

Table 2. Chemical compositions of basalt samples and the weathered zone (average).

LOI: Loss on ignition.

\begin{tabular}{ccccccccccc}
\hline Sample (\%) & $\mathbf{F e}_{2} \mathbf{O}_{3}$ & $\mathbf{N a}_{2} \mathbf{O}$ & $\mathbf{K}_{2} \mathbf{O}$ & $\mathbf{M g O}$ & $\mathbf{C a O}$ & $\mathbf{A l}_{2} \mathbf{O}_{3}$ & $\mathbf{T i O}_{2}$ & $\mathbf{M n O}$ & $\mathbf{L O I}$ & $\mathbf{S i O}_{2}$ \\
\hline Basalt & 4.27 & 2.97 & 2.46 & 4.37 & 7.30 & 15.64 & 0.45 & 0.11 & 2.54 & 59.84 \\
Altered Crust & 4.37 & 2.94 & 2.32 & 3.48 & 6.70 & 16.05 & 0.48 & 0.10 & 2.21 & 61.30 \\
\hline
\end{tabular}

\subsection{Tumbling Mill}

A tumbling mill is a cylindrical drum fitted with conical end plates on both sides. The drum is filled with steel balls occupying generally $30 \%$ of the volume. Mineral ore or rocks are fed on one end of the drum and discharged through the other. As the drum rotates, the balls and rocks tumble, which leads to grinding of the ore [15]. Tumbling mills with balls as grinding media are used in a variety of ways to produce fine powders. The fineness of powder produced in such mills depends on the powder strength characteristics as well as the impact energy of the tumbling balls [16]. The rocks in an autogenous mill initially wear relatively rapidly by breakage of the sharp protrusions and by fracture along planes of weakness [17,18].

Tumbling natural stones for ornamental purposes [19] and utilizing as grinding media is a common study subject. The alternative studies of designing a semi-autogenous and/or autogenous mill have also been performed [15,17,20-24].

Tumbling tests were performed by using a laboratory type rod mill (Figure 3). The mill was operated at $83 \mathrm{rpm}$, with a pulp density of $67 \%$ solid by weight. It is a well-known fact that water addition to a mill quickly reduces the power draw [25]. Three different size fractions of coarse, 
medium and fine particles were prepared in different proportions. It is known that control of the proportion of fines in the mill can be used to modify the rate of rock attrition [21]. The tumbling process was applied fully autogenously.

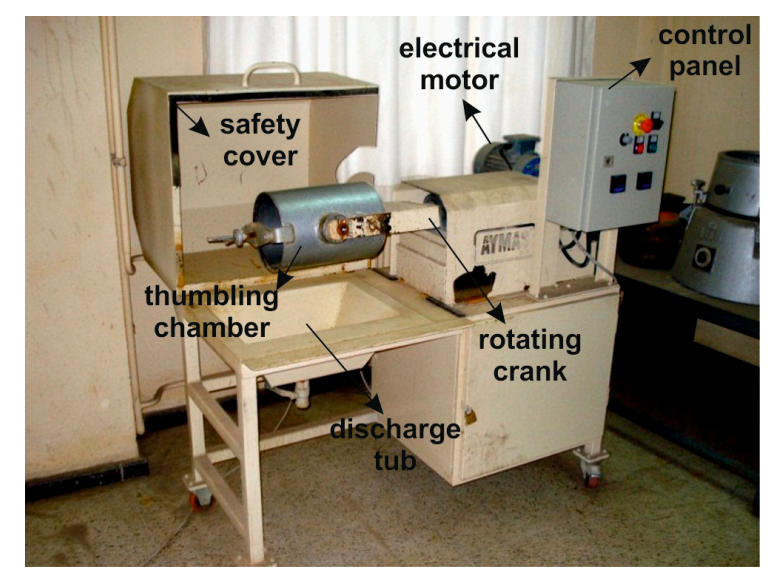

Figure 3. Laboratory type rod mill used as autogenous tumbling mill.

\subsection{Reflectance Analyses}

Upon interaction of electromagnetic radiation with a sample surface, depending on the characteristic of the surface and its environment, the light may undergo three types of reflection, internal, specular and diffuse reflection. In practice, all three types of reflections can occur at the same time, although with different contributions [26]. Simply, it is a measure of the percentage light reflected off the surface of an object. In a total spectroscopic analysis, the values of absorbance, transmittance and reflectance are all determined. Reflectance spectroscopy is a common analysis applied to pyrolytic igneous rocks such as basalt [27-29]. The reflectance analyses of original and altered coarse basalt samples were performed with a V-530 JASCO UV/VIS model spectrophotometer (JASCO Analytical Instruments, Mary's Court, Easton, MD, USA) in visible spectrum which is between 380 to $750 \mathrm{~nm}$ of wavelengths. The scale of reflectance changes from dark to light as 0.00 to 1.00 , respectively.

\section{Experimental Section}

The basalt waste-rock samples were classified into 3 particle size intervals, $+63 \mathrm{~mm},-22+12 \mathrm{~mm}$ and $-3+0.5 \mathrm{~mm}$. To distinctly compare the media mixture alternatives in cleaning the weathered surface of basaltic waste-rock particles, several experimental parameters such as tumbling speed, duration and solid-liquid ratio were fixed (Table 3).

Table 3. Fixed experimental tumbling parameters applied.

\begin{tabular}{cc}
\hline Parameter & Value \\
\hline Tumbling Speed (rpm) & 83 \\
Tumbling Duration (h) & 2 \\
Amount of Water (L) & 2 \\
Amount of Basalt (kg) & 4 \\
Solid Ratio (\%) & 67 \\
\hline
\end{tabular}


The mixing ratios of basaltic waste-rock particles and the produced material proportions are listed in Table 4 as well as the sample illustrations of particles before and after tumbling (Figure 4).

Table 4. Tumbled and produced rations of basalt in different particle sizes.

\begin{tabular}{|c|c|c|c|c|c|}
\hline \multirow{2}{*}{\multicolumn{2}{|c|}{ Experiment Code }} & \multirow{3}{*}{$\begin{array}{c}\text { Coarse }(+\mathbf{6 3} \mathbf{~ m m}) \\
\mathbf{( \% ,} \text { by weight }) \\
50.10\end{array}$} & \multirow{2}{*}{$\begin{array}{c}\text { Medium }(-22+12 \mathrm{~mm}) \\
(\%, \text { by weight })\end{array}$} & \multirow{2}{*}{$\begin{array}{c}\text { Fine }(-3+0.5 \mathrm{~mm}) \\
(\%, \text { by weight })\end{array}$} & \multirow{2}{*}{$\begin{array}{c}\text { Ultra-Fine }(-0.5 \mathrm{~mm}) \\
(\%, \text { by weight })\end{array}$} \\
\hline & & & & & \\
\hline \multirow{2}{*}{ MX-1 } & Before & & 24.93 & 24.97 & 0.00 \\
\hline & After & 48.48 & 22.64 & 3.73 & 25.15 \\
\hline \multirow{2}{*}{ MX-2 } & Before & 74.98 & 0.00 & 25.02 & 0.00 \\
\hline & After & 73.00 & 0.00 & 0.00 & 27.00 \\
\hline \multirow{2}{*}{ MX-3 } & Before & 49.88 & 0.00 & 50.12 & 0.00 \\
\hline & After & 44.97 & 0.00 & 20.22 & 34.81 \\
\hline \multirow{2}{*}{ MX-4 } & Before & 25.11 & 49.62 & 25.27 & 0.00 \\
\hline & After & 24.56 & 46.26 & 9.77 & 19.41 \\
\hline \multirow{2}{*}{ MX-5 } & Before & 24.98 & 25.04 & 49.98 & 0.00 \\
\hline & After & 21.23 & 3.26 & 1.00 & 74.51 \\
\hline \multirow{2}{*}{ MX-6 } & Before & 0.00 & 74.99 & 25.01 & 0.00 \\
\hline & After & 0.00 & 72.94 & 10.46 & 16.60 \\
\hline \multirow{2}{*}{ MX-7 } & Before & 75.07 & 24.93 & 0.00 & 0.00 \\
\hline & After & 73.34 & 12.44 & 0.00 & 14.22 \\
\hline \multirow{2}{*}{ MX-8 } & Before & 0.00 & 50.12 & 49.88 & 0.00 \\
\hline & After & 0.00 & 42.53 & 20.07 & 37.40 \\
\hline
\end{tabular}

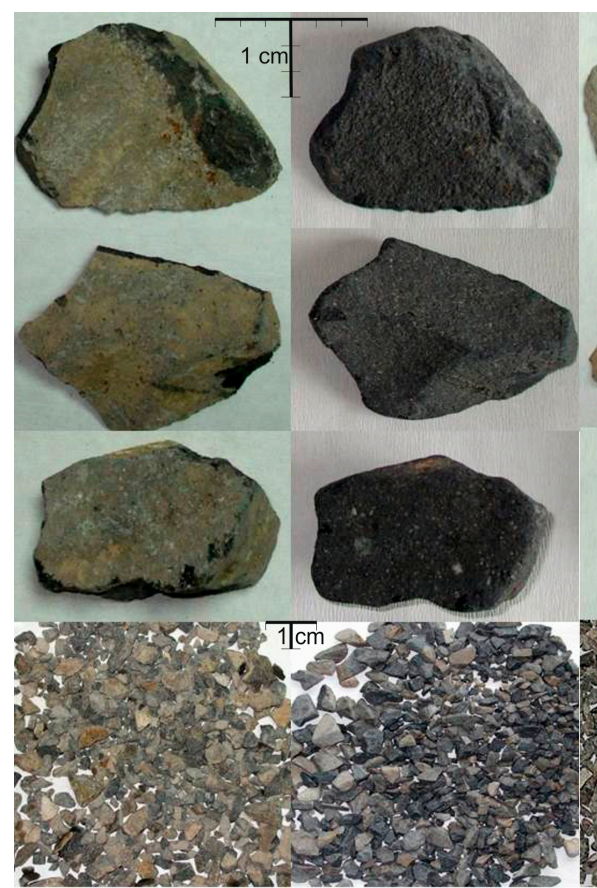

Before
After

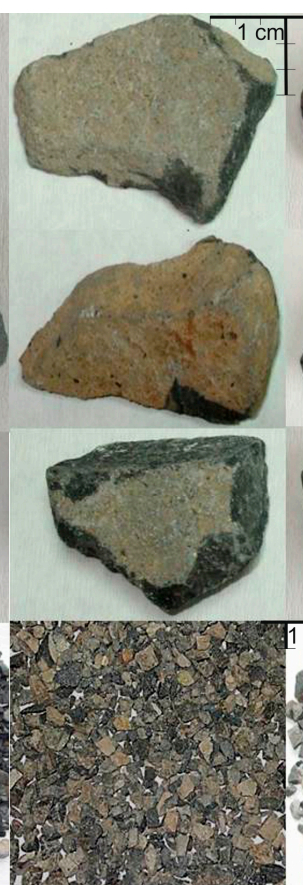

Before
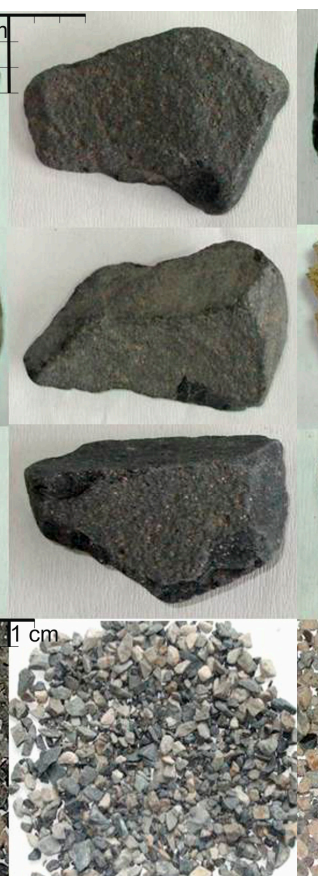

After
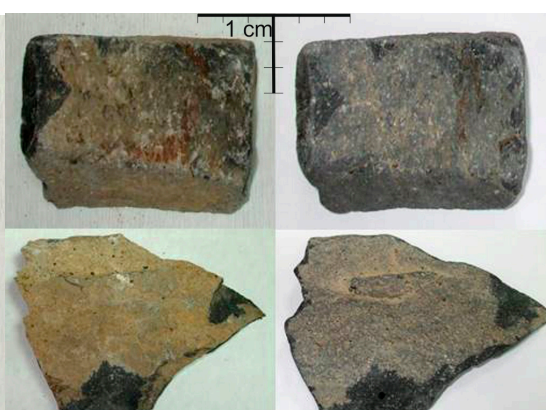

MX-4

Before
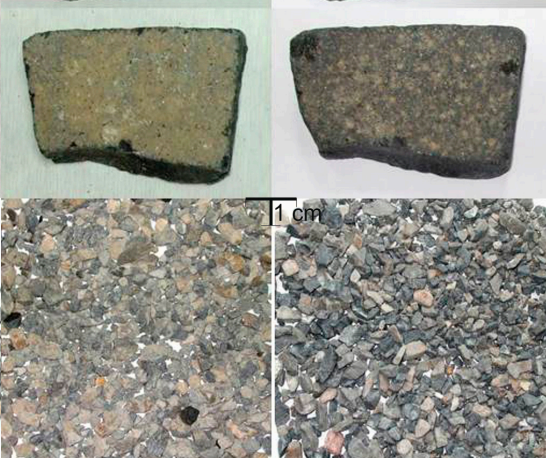

After

Figure 4. Particles of basaltic waste-rock before and after tumbling for MX-1, MX-4 and MX-7 mixtures (particles of $+63 \mathrm{~mm}$ coarse and $-22+12 \mathrm{~mm}$ medium size fractions). 


\section{Results and Discussion}

The weight distributions of tumbling feeds $(4 \mathrm{~kg})$ were set in eight different rations. Each basalt tailing mixture was evaluated with respect to weight loss and clean surface gathered. To begin with, MX-1 with $50.10 \%$ coarse, $24.93 \%$ medium and $24.97 \%$ fine basalt particles was tumbled and $25.15 \%$ of ultra-fine fraction mainly generated from the grinding of fine fraction was produced. The weight loss in the coarse and medium fraction was determined as $1.62 \%$ and $2.29 \%$, respectively. In addition, $21.24 \%$ of the fine fraction was ground during autogenous tumbling (Figure 5). It was detected that both shape and size of the coarse particles remained unchanged. The reflectance analysis of MX-1 also indicates that the weathered crust on the surface of basaltic waste-rock particles was almost completely abraded. The average reflectance of coarse particles in MX-1 was measured as 0.19 , where the primary unweathered sample was measured as 0.11 (Figure 6).

In MX-2, medium size fraction $(-22+12 \mathrm{~mm})$ was discarded and $74.98 \%$ of coarse fraction with $25.02 \%$ of fine fraction was tumbled. The weight loss in the coarse fraction was limited to $1.98 \%$; however, the fine fraction was totally turned ultra-fine in size. In addition, an unsatisfactory reflectance value of 0.32 was achieved. For MX-3 experiment, coarse and fine particles were changed to $49.88 \%$ and $50.12 \%$, respectively. An increase in the fine fraction resulted in a weight loss of $4.91 \%$ in the coarse fraction. Also, the weight of the fine fraction was diminished to $29.9 \%$ (Figure 5). Due to a large amount of fine fraction, a better reflectance value of 0.29 was achieved when compared to MX-2, but not as satisfactory as MX-1. In MX-4, the proportion of medium fraction was set to $49.62 \%$ where coarse and fine fractions were set to $25.11 \%$ and $25.27 \%$, respectively. The medium fraction did not cause a weight loss as in MX-3 in the coarse fraction. However, the reflectance values gathered were almost the same, 0.29 in MX-3 and 0.28 in MX-4 (Figure 6).

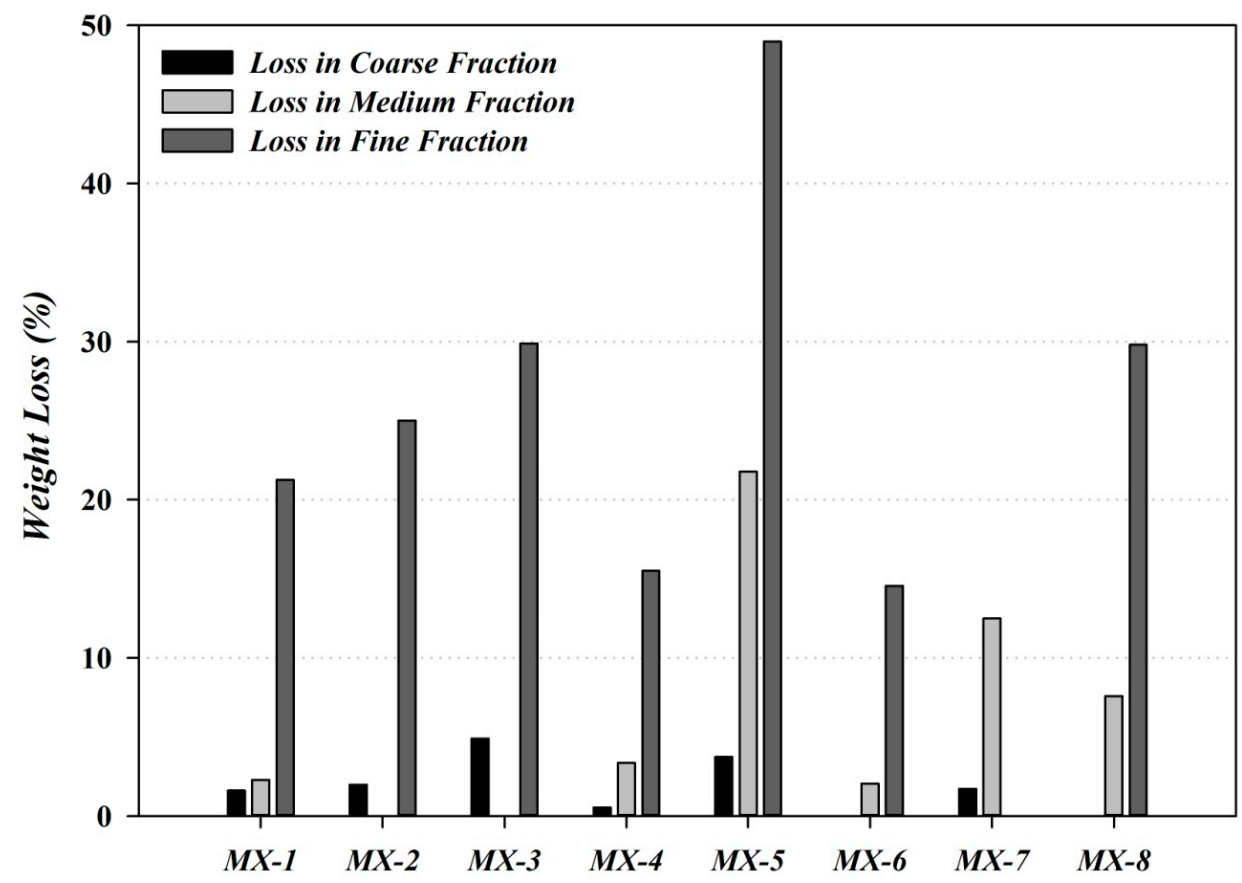

Figure 5. Weight loss (\%) of coarse, medium and fine size fractions of basaltic waste-rock particles as results of tumbling process trials using different feed compositions (MX-1 to MX-8). 


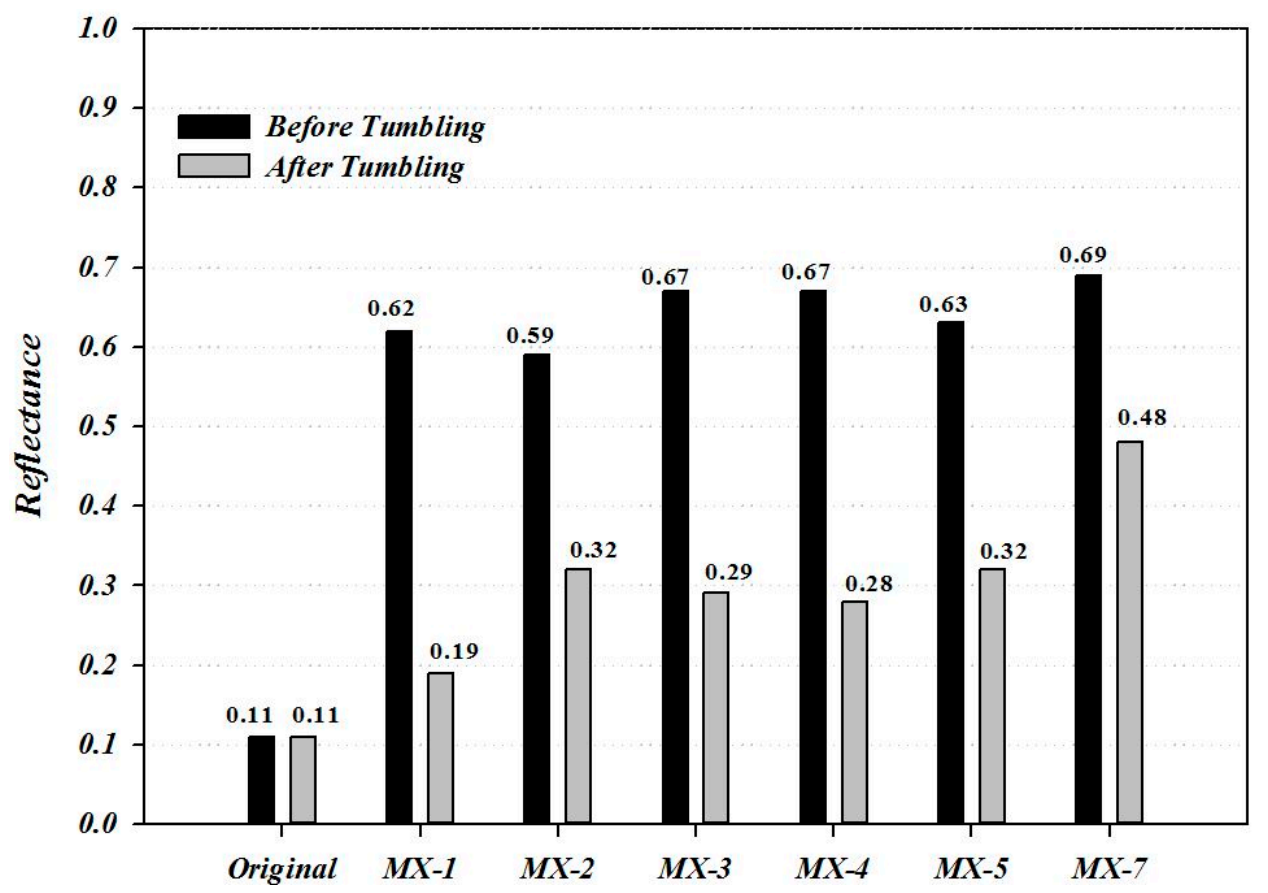

Figure 6. Reflectance measurements (average) of coarse size fraction of basaltic waste-rock before and after tumbling.

Tumbling tests performed with proportions of $24.98 \%$ coarse. $25.04 \%$ medium and $49.98 \%$ of fine fraction (MX-5) resulted with weight loss of 3.75\%, 21.78\% and 48.98\% for coarse, medium and fine fractions, respectively. Therefore, the fine fraction was almost diminished while significant losses were detected for both coarse and medium fractions. The scraping of weathered crust was not accomplished successfully and a reflectance value of 0.32 was obtained. Since the medium size fraction suffered high weight loss in experiments containing coarse size fraction, for MX-6 and MX-8 trials, the possibility of removing the weathered crust from the surfaces of medium sized particles was investigated. As a result, significant weight losses in medium size fraction were detected especially for MX-8 (50.12\% medium $-49.88 \%$ fine).

In most of the experiments, the fine size fraction was significantly to nearly diminished after tumbling. Therefore, in MX-7, only coarse and medium fractions were tumbled together $(75.07 \%$ coarse $-24.93 \%$ medium). A weight loss of $1.73 \%$ for the coarse fraction and $12.49 \%$ for the medium fraction was calculated. The highest reflectance value, suggesting the removal of weathered crust was not accomplished properly, was measured in MX-7 (Figure 6). Moreover, even the visuals of the coarse rocks in Figure 4 prove the unsuccessful tumbling.

\section{Conclusions}

Autogenous tumbling process was used to remove weathered crust on surfaces of basaltic waste-rock particles. Several different feed compositions, formed by three different particle size fractions were experimented to determine the most suitable mixture in cleaning out the surfaces of basalt waste-rock particles. Therefore, by only benefiting from basalt waste-rock particles themselves, it would be possible to reutilize these dumpsites resulted from cutting the weathered outer surface of basalts. 
The inefficiently cut out portions of basalt are indeed value-added inputs for different fields of industry. Hence, minimum loss of commercially available basalt pieces and maximum clear surface produced should be the objective of the tumbling process. In determination of the proportions of feed materials, we referred to weight loss in percent and reflectance analyses.

It was detected that, the higher the fine fraction is, the more the loss of commercially available product fraction diminishes. The experiment MX-1 (50.10\% coarse, $24.93 \%$ medium and $24.97 \%$ fine fraction) was revealed to be the optimum feed composition for a tumbling process in preventing both the economic loss and environmental disturbance by the lowest reflectance value gathered (which is positively favorable for primary, unweathered basalt samples) and reasonable loss of valuable size fractions without any addition of wearable grinding media other than natural basalt.

\section{Conflicts of Interest}

The author declares no conflict of interest.

\section{References}

1. Önem, Y. Industrial Minerals, 1st ed.; Kozan Ofset Publishing: Ankara, Turkey, 1997; pp. 329-330.

2. Yılmaz, S.; Özkan, O.T.; Günay, V. Crystallization kinetics of basalt glass. Ceram. Int. 1996, 22, 477-481.

3. Yıldız, S.; Isık, N.; Kelestemur, O. Investigating the mechanical properties of Diyarbakır basalts. Sci. Eng. J. Firat Univ. 2008, 20, 617-626. (In Turkish)

4. Karaca, M.; Asagıcayır, D. Heat Deposition Properties of Basalt. Master's Thesis, Afyon Kocatepe University, Afyonkarahisar, Turkey, 2003. (In Turkish)

5. Esder, T.; Ciçekli, K.; Sarıkaya, H.; Yakabagı, A. Annual Report on Geology and Geothermal Energy Possibilities of Aliaga, Izmir; General Directorate of Mineral Research \& Exploration: Ankara, Turkey, 1991. (In Turkish)

6. Kibici, Y. Petrography and mineralogy of basic and ultrabasic rocks. In Proceedings of the 4th Marble Symposium, Izmir, Turkey, 18-19 December 2003. (In Turkish)

7. Özkan, R.; Şener, M.; Helvac1, C.; Şener, M.F. Hydrothermal alterations and relationship with thermal waters at Aliaga (Izmir). Bull. Earth Sci. Appl. Res. Cent. Hacet. Univ. 2011, 32, 1-20.

8. Temur, S.; Temur, Y.; Kansun, G. Geological, petrographical and technological investigation of Erkilet basalts. J. Geol. Eng. 2007, 31, 1-7. (In Turkish)

9. Günerhan, H.; Hepbasli, A. Utilization of basalt stone as a sensible heat storage material. Energy Sources 2005, 27, 1357-1366.

10. Wu, S.; Xue, Y.; Ye, Q.; Chen, Y. Utilization of steel slag as aggregates for stone mastic asphalt (SMA) mixtures. Build. Environ. 2007, 42, 2580-2585.

11. Aldur Basalt Mining Company. Available online: http://aldur.com.tr/L/EN/ (accessed on 11 March 2015).

12. Meda Construction Company. Available online: http://www.medayapi.com.tr/ (accessed on 11 March 2015). 
13. British Standards Institution. Natural Stone Test Methods, Determination of Uniaxial Compressive Strength; BS EN 1926:2006; British Standards Institution: London, UK, 2007.

14. British Standards Institution. Natural Stone Test Methods, Determination of Abrasion Resistance; CSN EN 14157; British Standards Institution: London, UK, 2004.

15. Mula, A.L.; Jergensen, G.V. Design and Installation of Comminution Circuits; Society of Mining Engineers Press: New York, NY, USA, 1982; pp. 393-401.

16. Rajamani, R.K.; Songfack, P.; Mishra, B.K. Impact energy spectra of tumbling mills. Powder Technol. 2000, 108, 116-121.

17. Loveday, B.K.; Dong, H. Optimization of autogenous grinding mills. Miner. Eng. 2000, 13, 1341-1348.

18. Naidoo, D. A Laboratory-Scale Investigation of Factors Affecting Autogenous Milling. Master's Thesis, University of Natal, Durban, South Africa, 2000.

19. Symes, R.F. Eyewitness Rocks and Minerals; Dorling Kindersley Limited: London, UK, 1988.

20. Morrell, S.; Finch, W.M.; Kojovic, T.; Delboni, H. Modelling and simulation of large diameter autogenous and semi-autogenous mills. Int. J. Miner. Process. 1996, 44-45, 289-300.

21. Loveday, B.K.; Naidoo, D. Rock abrasion in autogenous milling. Miner. Eng. 1997, 10, 603-612.

22. Rajamani, R.K.; Mishra, B.K.; Venugopal, R.; Datta, A. Discrete element analysis of tumbling mills. Powder Technol. 2000, 109, 105-112.

23. Morrell, S. A new autogenous and semi-autogenous mill model for scale-up, design and optimization. Miner. Eng. 2004, 17, 437-445.

24. Salazar, J.L.; Magne, L.; Acuna, G.; Cubillos, F. Dynamic modelling and simulation of semi-autogenous mills. Miner. Eng. 2009, 22, 70-77.

25. Valery, W.; Morrell, S. The development of a dynamic model for autogenous and semi-autogenous grinding. Miner. Eng. 1995, 8, 1285-1297.

26. Khoshhesab, Z.M. Reflectance IR Spectroscopy. Available online: http://cdn.intechopen.com/ pdfs-wm/36176.pdf (accessed on 11 June 2015).

27. Mustard, J.F.; Hays, J.E. Effects of Hyperfine Particles on Reflectance Spectra from 0.3 to $25 \mu \mathrm{m}$. Icarus 1997, 125, 145-163.

28. Glotch, T.D.; Rossman, G.R.; Aharonson, O. Mid-infrared $(5-100 \mu \mathrm{m})$ reflectance spectra and optical constants of ten phyllosilicate minerals. Icarus 2007, 192, 605-622.

29. Bishop, J.L.; Lane, M.D.; Dyar, M.D.; Brown, A.J. Reflectance and emission spectroscopy study of four groups of phyllosilicates: smectites, kaolinite-serpentines, chlorites and micas. Clay Miner. 2008, 43, 35-54.

(C) 2015 by the authors; licensee MDPI, Basel, Switzerland. This article is an open access article distributed under the terms and conditions of the Creative Commons Attribution license (http://creativecommons.org/licenses/by/4.0/). 